\title{
Examining the psychometric properties of the Body Appreciation Scale-2 in Brazilian adolescents
}

\author{
Manuel ALCARAZ-IBÁÑEZ ${ }^{1}$, João Guilherme CREN CHIMINAZZO \\ Álvaro SICILIA ${ }^{1}$, Paula TEIXEIRA FERNANDES ${ }^{2}$ \\ ${ }^{1}$ Universidad de Almería. España \\ ${ }^{2}$ Universidade Estadual de Campinas. Brasil
}

(Received May 1, 2017; Accepted September 5, 2017)

\begin{abstract}
This study examined the psychometric properties of the Body Appreciation Scale-2 (BAS-2) in Brazilian adolescents. The sample was comprised of 438 boys $\left(M_{\text {age }}=15.50, S D_{\text {age }}=1.20\right)$ and 402 girls $\left(M_{a g e}=15.51, S D_{a g e}=1.18\right)$. Confirmatory factor analyses supported a one-dimensional and partially invariant across-gender and weight status factor structure. The instrument showed adequate internal consistency and temporal stability over a two-week period. Body appreciation was negatively correlated with social physique anxiety and body mass index in both boys and girls. After controlling for social physique anxiety, body appreciation was positively and significantly correlated with life satisfaction in both genders. Significantly higher levels of body appreciation scores were found in men compared to women $(d=.48)$ as well as in underweight and normoweight adolescents compared to the overweight and obese adolescents $(d=.50)$. These findings suggest that the BAS-2 is a valid and reliable instrument to assess body appreciation in Brazilian adolescents. The BAS-2 could be useful for attaining a deeper insight into positive body image research as well as for improving clinical practice in the Brazilian context.
\end{abstract}

Keywords: Positive body image; factorial validity; cultural equivalence.

\section{Análisis de las Propiedades Psicométricas de la Escala de Apreciación Corporal-2 en Adolescentes Brasileños}

RESUMEN: Este estudio examinó las propiedades psicométricas de la Escala de Apreciación Corporal-2 (BAS-2) en adolescentes brasileños. La muestra incluyó 438 chicos $\left(M_{\text {edad }}=15.50, D T_{\text {edad }}\right.$ $=1.20)$ y 402 chicas $\left(M_{\text {edad }}=15.51, D T_{\text {edad }}=1.18\right)$. El análisis factorial confirmatorio realizado apoyó la estructura unidimensional e invariante en función del género y el estado de peso. El instrumento mostró adecuados niveles de consistencia interna y estabilidad temporal en un periodo de dos semanas. La apreciación corporal correlacionó de forma negativa con la ansiedad físico social y el índice de masa corporal tanto en chicos como en chicas. Una vez controlados los efectos de la ansiedad físico social, la apreciación corporal correlacionó de forma positiva y estadísticamente significativa con la satisfacción vital en ambos géneros. Se observó la existencia de mayores niveles de apreciación corporal tanto en chicos respecto a chicas $(d=.48)$ como en los adolescentes con niveles de bajo peso y normopeso respecto a los que mostraban sobrepeso u obesidad $(d=.50)$. Estos resultados apoyan el uso 
de la BAS-2 como un instrumento válido y fiable para medir apreciación corporal en adolescentes brasileños. La BAS-2 podría resultar de utilidad tanto para la investigación en el ámbito de la imagen corporal positiva como para la práctica clínica en el contexto brasileño.

Palabras clave: Imagen corporal positiva; validez factorial; cultural equivalence.

Correspondencia: ${ }^{1}$ Manuel Alcaraz-Ibáñez, Universidad de Almería, Facultad de Ciencias de la Educación, Carretera de Sacramento s/n, 04120 La Cañada de San Urbano (Almería), Spain. Tel: +34+950 0155394, Fax: +34+950 015751. Email: manuelalcaraz74@,gmail.com

\section{Introduction}

Over recent years, body image research has evolved from considering only negative and pathologically-related aspects to a broader conceptualization that includes positive body image constructs (Tylka \& Wood-Barcalow, 2015b). Defined as the intentional choice to accept and respect one's body and to reject unrealistic appearance ideals (Avalos, Tylka, \& WoodBarcalow, 2005), body appreciation has been one of the most widely investigated positive body image constructs (Webb, Wood-Barcalow, \& Tylka, 2015).

To measure body appreciation, Avalos et al. (2005) proposed the Body Appreciation Scale (BAS). However, some limitations of this instrument, such as the existence of items that assume that individuals view imperfections in their bodies, gender-specific and low loading items, or the emergence of a non-interpretable second factor in several non-Western cultural contexts, have been pointed out (Tylka \& Wood-Barcalow, 2015a). To solve these limitations, Tylka and Wood-Barcalow (2015a) proposed a revised version of the BAS (BAS-2) that includes 5 items from the original scale and 5 newly developed. This instrument showed a one-dimensional and invariant across-gender factor structure, as well as high levels of internal consistency $(\geq .93)$ and temporal stability over a three-week period $(r=.90)$. Furthermore, BAS-2 scores positively explained unique variance in self-esteem over body dissatisfaction for both men and women. Regarding gender differences, men showed slightly higher body appreciation levels than women in both undergraduate $(d=.27$ and .58$)$ and community $(d=.11$ and .26$)$ samples.

To date, the psychometric properties of BAS-2 have been examined in different countries and cultural contexts. For example, the one-dimensional factor structure of BAS-2 has been supported in Dutch-speaking (Alleva, Martijn, Veldhuis, \& Tylka, 2016), Cantonese-speaking (Swami \& NG, 2015), French-speaking (Kertechian \& Swami, 2017), and Romanian-speaking (Swami, Tudorel, Goian, Barron, \& Vintila, 2017) undergraduates, as well as in Spanishspeaking (Swami, Alías García, \& Barron, 2017), Standard Chinese-speaking (Swami, Ng, \& Barron, 2016) and Polish-speaking (Razmus \& Razmus, 2017) adults. This one-factor structure has also proved to be invariant across gender (Kertechian \& Swami, 2017; Razmus \& Razmus, 2017; Swami, Alías García, et al., 2017; Swami \& NG, 2015), being the Romanian translation (Swami, Tudorel, et al., 2017) the solely exception to this tendency. Regarding reliability, these studies have reported high internal consistency values (from .86 to.92), as well as adequate levels of temporal stability over a three-week period (Swami, Tudorel, et al., 2017). Additionally, and despite the effect size being small, these studies have shown that men tend to report higher body appreciation levels than women (e.g. $d_{\text {Iran }}=0.15 ; d_{\text {Hong-Kong }}=0.19$; 
$d_{\text {China }}=0.16, d_{\text {France }}=0.16$ and $\left.0.19 ; d_{\text {Spain }}=0.04\right)$. Moreover, these studies have found positive associations between BAS-2 scores and well-being indicators such as life satisfaction (Alleva et al., 2016; Atari, 2016; Swami et al., 2016; Swami \& NG, 2015), as well as negative associations with BMI (Alleva et al., 2016; Atari, 2016; Razmus \& Razmus, 2017) and body and weight dissatisfaction (Razmus \& Razmus, 2017; Swami et al., 2016). Finally, Alleva et al. (2016) reported that BAS-2 scores made an incremental contribution to self-esteem over other positive body image-related constructs in a sample of Dutch-speaking undergraduates, therefore providing evidence of incremental validity for the instrument.

Despite the results of the above mentioned research works support the BAS-2 as a valid and reliable instrument to measure body appreciation, some limitations regarding its ongoing validation process should be highlighted. First, no study to date has so far examined the psychometric proprieties of the instrument in adolescent population. This lack of research in the literature is somehow surprising, mainly, considering that adolescence is a critical period in the development of both negative and positive body image (Voelker, Reel, \& Greenleaf, 2015). Second, the association between weight status and body image has been extensively documented. Consequently, elucidating whether instruments measuring body image are interpreted equivalently by individuals with different weight status has been a matter of interest for research (Sáenz-Alvarez, Sicilia, González-Cutre, \& Ferriz, 2013). However, no evidence supporting the invariant character across weight status for the BAS-2 has been provided to date. Finally, the psychometrics proprieties of the BAS-2 has not yet been tested in some of the cultural contexts in which the original version of the instrument (Avalos et al., 2005) failed to show a one-dimensional structure (e.g., the Brazilian one; Swami et al., 2011).

As a contribution to the body image literature, the aim of this study was to examine the psychometric properties of the BAS-2 in Brazilian adolescents. Given the existing body of theoretical and empirical research postulating a one-factor structure for the BAS-2, factorial validity was analyzed using the CFA technique. It was also expected that the one-factor structure would be invariant across gender and weight status. Furthermore, it was hypothesized that the instrument would show a good level of internal consistency and temporal stability over a two-week period. In order to provide evidence of construct validity, body appreciation was expected to be positively correlated with life satisfaction and negatively correlated with social physique anxiety and BMI. It was also hypothesized that body appreciation would be positively and significantly correlated with life satisfaction after controlling for the effect of social physique anxiety in both boys and girls. Finally, it was hypothesized that BAS-2 scores would be moderately higher in boys than girls.

\section{Method}

\section{Participants}

The sample was comprised of 840 students ( 438 boys and 402 girls) from three Brazilian cities located in São Paulo State. Participant ages ranged from 13 to 17 years, with a mean age of 15.50 $(S D=1.20)$ for boys and $15.51(S D=1.18)$ for girls. Their self-reported BMI ranged from 13.55 to $43.98 \mathrm{~kg} / \mathrm{m}^{2}$, being their mean BMI of $21.87(S D=3.52)$ for boys and $21.67(S D=3.71)$ for 
girls. To analyse BAS-2's temporal stability, a second independent sample of students comprising 19 boys and 27 girls $\left(M_{a q e}=14.02, S D_{a q e}=0.93, M_{B M I}=20.32, S D_{B M I}=3.03\right)$ completed the instrument twice within a two-week period.

\section{Measures}

Body Appreciation. Participants completed a Brazilian Portuguese translation (see Table 1) of the BAS-2 (Tylka \& Wood-Barcalow, 2015a). The instrument comprises 10 items rated on a 5point Likert-type scale $(1=$ Never, $5=$ Always $)$.

Social Physique Anxiety. Participants completed the Portuguese version for adolescents (Calmeiro, Simões, Gaspar de Matos, \& Gamito, 2012) of the Social Physique Anxiety Scale (Motl \& Conroy, 2000). The instrument comprises six items (e.g. "It would make me uncomfortable to know others were evaluating my physique or figure") rated on a 5-point Likert-type scale $(1=$ Never, $5=$ Always $)$. In this study, composite reliability scores $(\rho)$ of .90 (boys) and .89 (girls) were obtained.

Life Satisfaction. Participants completed the Portuguese version validated in Brazilian adolescent population (Zanon, Bardagi, Layous, \& Hutz, 2014) of the Satisfaction with Life Scale (SWLS; Diener, Emmons, Larsen, \& Griffin, 1985). The instrument comprises five items (e.g. "I am satisfied with my life") rated on a 7-point Likert-type scale ( 1 = Strongly disagree, 5 $=$ Strongly agree). In this study, values of $\rho=.88$ (boys) and $\rho=.86$ (girls) were obtained.

Demographics. Participants reported their gender, age, height, and weight. Their BMI $\left(\mathrm{kg} / \mathrm{m}^{2}\right)$ was computed using their self-reported weight and height. Cut-off values for BMI proposed by Conde and Monteiro (2006) for Brazilian adolescent were used to classify the participants as underweight, normoweight, overweight and obese.

\section{Procedure}

First, a back-translation procedure was performed; this included the following steps: (a) the authors of the study independently translated the scale from English to Brazilian Portuguese, obtaining a final version by consensus; (b) an independent bilingual translator translated the Brazilian Portuguese version back into English; and (c) the translation and back-translations were reviewed by a bilingual psychologist who did not suggest further adjustments. After obtaining the approval from the Bioethics Committee of the University of Campinas, participants were recruited in classroom settings. Given that participants were minors, prior parental consent to participate in the research was required. After being informed about the voluntary and confidentially nature of their participation, those students who agreed to take part in the research completed a paper-and-pencil version of the questionnaire in a classroom environment.

\section{Statistical Analyses}

The hypothesized one-factor BAS-2 solution was analyzed using a confirmatory factor analysis (CFA). Given the ordered polytomous character of the variables, a weighted least squares mean- and variance-adjusted (WLSMV) estimation method procedure using the polychoric (c) Psy, Soc, \& Educ, 2017, Vol. 9(3) 
correlation matrix was employed. This method provides robust standard errors in CFA employing ordinal variables even with non-normal data ( $\mathrm{Li}, 2015)$. Due to the likely nesting of the students the COMPLEX function and the cluster option (based on the different school centres) of Mplus were employed (Muthén \& Muthén, 1998-2015).Values for the comparative fit index (CFI) and the Tucker-Lewis index (TLI) greater than .95 indicate an excellent fit; values for the root mean square error of approximation (RMSEA) not exceeding .06 and .10, respectively, indicate an excellent or minimally acceptable fit (West, Taylor, \& Wu, 2012). To examine whether BAS-2 was invariant across gender and weight status, both configural (i.e. the equivalent factorial structure or M0) and the metric-scalar level (i.e. equivalent factor loadings and item thresholds or M1) were tested. Because the item characteristic curve is influenced both by factor loading and thresholds, metric and scalar levels were simultaneously tested (Muthén \& Muthén, 1998-2015). Significant changes $(p<.05)$ in the chi-square value $(\Delta \chi 2)$ using the DIFFTEST procedure in Mplus was considered indicative of non-invariance.

Given the limitations of Cronbach's alpha coefficient, internal reliability was assessed using composite reliability $(\rho)$ derived from CFA (Raykov, 2004). Temporal stability was analyzed using the intraclass correlation coefficient (ICC) and bivariate correlations. To obtain evidence of convergent and incremental validity, bivariate and partial correlations among BAS-2 scores and the remaining study variables were respectively obtained. Finally, gender and weight status differences in the latent BAS-2 scores were investigated through a multiple-cause-multipleindicator model $(\mathrm{MIMIC})$ in which gender ( girls $=0$, boys $=1$ ) and weight status (underweight and normoweight $=0$, overweight and obese $=1$ ) were simultaneously specified as external indicators whereas BAS-2 latent score was specified as the independent variable. This procedure allows to evaluate differences in latent means scores controlling for the effect of all other independent variables (Brown, 2015). Effects sizes for the difference $(d)$ of 0.2, 0.5, and 0.8 were considerate as small, moderate and large, respectively (Cohen, 1988). IBM SPSS v.22 and Mplus v.7 software packages were used for the statistical analyses.

\section{Results}

\section{Confirmatory Factor Analysis}

The hypothesized 10 item one-factor model showed an acceptable fit to the data for the whole sample as well as for both gender and weight status subsamples (see Table 2). However, statistically-significant differences between M0 and M1 $(p=.01)$ were found in the DIFFTEST procedure used to test invariance across gender. Further inspection of the modification indices suggested that the model fit could be improved if the thresholds \#1 of the item \#9 and \#3 of the item \#2 were freed (M1P). After performing this modification, no statistically-significant differences were found between M0 and M1P $(p=.07)$. No statistically-significant differences were found between M0 and M1 $(p=.33)$ in the DIFFTEST procedure used to test invariance across weight status. 
Table 1. Factor Loadings and Standard Errors for Whole Sample and Gender and Weight Status Subgroups

English BAS-2 items [Spanish version]

\begin{tabular}{|c|c|c|c|c|c|c|c|c|c|}
\hline \multicolumn{2}{|c|}{$\begin{array}{l}\text { Whole sample } \\
\qquad(\mathrm{N}=840)\end{array}$} & \multicolumn{2}{|c|}{$\begin{array}{c}\text { Boys } \\
(n=438)\end{array}$} & \multicolumn{2}{|c|}{$\begin{array}{c}\text { Girls } \\
(n=402)\end{array}$} & \multicolumn{2}{|c|}{$\begin{array}{c}\text { UW \& } \\
\text { NW } \\
(n=592)\end{array}$} & \multicolumn{2}{|c|}{$\begin{array}{c}\text { OW \& } \\
\text { OB } \\
(n=248)\end{array}$} \\
\hline$\lambda$ & $\mathrm{SE}$ & $\lambda$ & SE & $\lambda$ & SE & $\lambda$ & SE & $\lambda$ & SE \\
\hline .74 & .02 & .65 & .05 & .80 & .02 & .65 & .03 & .71 & .01 \\
\hline .87 & .01 & .82 & .02 & .92 & .01 & .88 & .03 & .87 & .02 \\
\hline .83 & .03 & .73 & .04 & .86 & .03 & .65 & .01 & .76 & .01 \\
\hline .90 & .01 & .85 & .02 & .93 & .01 & .87 & .01 & .85 & .01 \\
\hline .66 & .03 & .64 & .04 & .70 & .04 & .53 & .06 & .60 & .06 \\
\hline .86 & .01 & .76 & .03 & .91 & .01 & .79 & .02 & .83 & .02 \\
\hline .81 & .01 & .78 & .02 & .85 & .01 & .70 & .00 & .81 & .02 \\
\hline .74 & .02 & .70 & .03 & .76 & .02 & .69 & .02 & .74 & .02 \\
\hline .90 & .01 & .84 & .02 & .94 & .01 & .88 & .03 & .78 & .02 \\
\hline .73 & .02 & .63 & .02 & .80 & .02 & .75 & .03 & .72 & .01 \\
\hline
\end{tabular}

1. I respect my body [Respeito o meu corpo]

2. I feel good about my body [Sinto-me bem com o meu corpo]

3. I feel that my body has at least some good qualities [Sinto que o meu corpo tem pelo menos algumas qualidades]

4. I take a positive attitude towards my body [Tenho uma atitude positiva em relação ao meu corpo]

5. I am attentive to my body's needs [Estou atento(a) às necessidades do meu corpo]

6. I feel love for my body [Eu sinto amor pelo meu corpo]

7. I appreciate the different and unique characteristics of my body [Aprecio as características diferentes e únicas do meu corpo]

8. My behaviour reveals my positive attitude toward my body; for example, I hold my head high and smile [O meu comportamento revela uma atitude positiva em relação ao meu corpo]

9. I am comfortable in my body [Sinto-me confortável no meu corpo]

10. I feel like I am beautiful even if I am different from media images of attractive people (e.g., models, actresses/actors) [Sinto que sou bonito(a), mesmo sendo diferente das imagens de pessoas divulgadas na mídia (ex. modelos ou atrizes/atores)]

Note: $\lambda=$ Standardized factor loadings, $\mathrm{SE}=$ Standard errors; $\mathrm{UW}=$ Underweight; $\mathrm{NW}=$ Normoweight; OW $=$ Overweight; OB $=$ Obese. All factor loadings were statically significant $(p<.001)$. 
Table 2. Model Fit Indices for the Confirmatory Factor Analyses and tests of Measurement Invariance

\begin{tabular}{|c|c|c|c|c|c|c|c|c|c|c|}
\hline \multirow{2}{*}{ Model } & \multirow{2}{*}{$\chi^{2}$} & \multirow{2}{*}{$d f$} & \multirow{2}{*}{$\chi^{2} / d f$} & \multicolumn{3}{|c|}{ DIFFTEST } & \multirow{2}{*}{ Models compared } & \multirow{2}{*}{ CFI } & \multirow{2}{*}{ TLI } & \multirow{2}{*}{ RMSEA (IC90\%) } \\
\hline & & & & $\Delta \chi^{2}$ & $\Delta d f$ & $p$ & & & & \\
\hline Whole sample & 288.33 & 35 & 8.24 & - & - & - & - & .980 & .975 & $.081(.072, .092)$ \\
\hline Boys $(n=438)$ & 167.21 & 35 & 4.78 & - & - & - & - & .970 & .962 & $.093(.079, .107)$ \\
\hline Girls $(n=402)$ & 105.14 & 35 & 3.00 & - & - & - & - & .990 & .987 & $.071(.055, .086)$ \\
\hline M0: Configural invariance (Gender) & 208.20 & 70 & 3.88 & - & - & - & - & .997 & .996 & $.069(.058, .079)$ \\
\hline M1: Metric + Scalar invariance (Gender) & 212.95 & 108 & 1.97 & $64.41^{\mathrm{a}}$ & 38 & .01 & M1 vs. M0 (Gender) & .998 & .998 & $.056(.045, .067)$ \\
\hline M1P: Partial Metric + Scalar invariance & 201.22 & 106 & 1.90 & $49.08^{\mathrm{a}}$ & 36 & .07 & M1P vs. M0 (Gender) & .998 & .998 & $.046(.036, .056)$ \\
\hline Underweight \& Normoweight group $(n=592)$ & 75.72 & 35 & 2.16 & - & - & - & - & .993 & .991 & $.044(.031, .058)$ \\
\hline Overweight \& Obese group $(n=248)$ & 141.25 & 35 & 4.04 & - & - & - & - & .999 & .998 & $.111(.092, .130)$ \\
\hline M0: Configural invariance (Weight status) & 197.96 & 70 & 2.80 & - & - & - & - & .998 & .998 & $.066(.055, .077)$ \\
\hline M1: Metric + Scalar invariance (Weight status) & 172.84 & 108 & 1.69 & 41.32 & 38 & .33 & M1 vs. M0 (Weight status) & .999 & .999 & $.038(.027, .048)$ \\
\hline
\end{tabular}

${ }^{a}$ Given DIFFEST procedure was employed, $\Delta \chi 2$ is not equal to the difference between $\chi 2$ values for the two nested models. 


\section{Reliability Analyses}

The composite reliability values for the BAS-2 were $\rho=.93$ for both boys and girls. Temporal stability analyses $(n=46)$ showed ICC values of $.98(95 \% \mathrm{CI}=.97, .99)$ between the first and second application of the BAS-2.

\section{Convergent-Incremental Validity and Gender Differences}

Negative correlations were found between body appreciation and (a) social physique anxiety $\left(r_{\text {boys }}=-.63 ; r_{\text {girls }}=-.67\right.$; both $\left.p<.001\right)$ and (b) BMI $\left(r_{\text {boys }}=-.20 ; r_{\text {girls }}=-.25 ;\right.$ both $\left.p<.001\right)$. Positively correlations were found between body appreciation and life satisfaction $\left(r_{\text {boys }}=.49\right.$; $r_{\text {girls }}=.56$; both $p<.001$ ). For boys, the correlation between body appreciation and life satisfaction remained significant $\left(r_{(\mathrm{BAS}-2)(\mathrm{LS}) \text {.SPAS }}=.42, p<.001\right)$ after controlling for social physique anxiety $\left(r_{\text {(SPAS)(LS).BAS- } 2}=.06, p=.23\right)$ For girls, correlations between body appreciation and life satisfaction remained significant $\left(r_{(\mathrm{BAS}-2)(\mathrm{LS}) . \mathrm{SPAS}}=.49, p<.001\right)$ after controlling for social physique anxiety $\left(r_{(\mathrm{SPAS})(\mathrm{LS}) \mathrm{BAS}-2}=.08, p=.10\right)$. Finally, significant gender and weight status differences in body appreciation were found. Specifically, boys showed moderately higher levels of body appreciation than girls $(\beta=.24, p<.001, d=0.48)$. Likewise, the group of underweight and normoweight adolescents showed moderately higher levels of body appreciation than the group of overweight and obese adolescents $(\beta=.25, p<$ $.001, d=0.50)$. According to the results of invariance analyses, one additional MIMIC model excluding the items that were partially invariant across gender (i.e. \#2 and \#9) was specified. The comparison of standardized regression weights using Fisher's $Z$ transformations reveals that the effect size of the differences in BAS-2 scores calculated including or excluding partially invariant items $\left(Q_{\text {Cohen }}=.01\right)$ was quite below the cut-off point of .10 therefore it can be considered negligible (Cohen, 1988).

\section{Discussion}

This study examined the psychometric properties of a Brazilian Portuguese translation of the BAS-2 in Brazilian adolescents. As found by previous research conducted in western (Alleva et al., 2016; Kertechian \& Swami, 2017; Tylka \& Wood-Barcalow, 2015a) and non-western cultures (Atari, 2016; Swami et al., 2016; Swami \& NG, 2015), our results revealed a onedimensional factor structure for BAS-2. In line with past research (Kertechian \& Swami, 2017; Tylka \& Wood-Barcalow, 2015a) this structure was invariant across gender.

Reliability for the BAS-2 in Brazilian adolescents was supported by adequate levels of internal consistency as well as high temporal stability over a two-week period. These finding is relevant given that it is the first time that the reliability of the BAS-2 has been examined in adolescent population. Moreover, the instrument showed convergent validity based on: (a) the negative correlations found with social physique anxiety and BMI, and (b) the positive correlation found with life satisfaction. In line with previous research that considered undergraduate females (Alleva et al., 2016) or gender-mixed samples of undergraduates (Tylka \& Wood-Barcalow, 2015a), body appreciation contributed to explain a positive global functioning indicator (i.e. life satisfaction) beyond body dissatisfaction. These results provide for the first time evidence 
of incremental validity for the BAS-2 in adolescent population. Our findings also suggest that body appreciation may contribute to an increase in positive global well-being in both boys and girls. However, research has defined global well-being as a complex construct that comprises several lower order indicators such as, for example, happiness, vitality, or optimism (Longo, Coyne, \& Joseph, 2017). Consequently, future research should explore and clarify the contribution of body appreciation in the development of several well-being-related outcomes.

Consistent with past research conducted with samples of undergraduates (Atari, 2016; Kertechian \& Swami, 2017; Swami \& NG, 2015; Tylka \& Wood-Barcalow, 2015a), boys showed moderately higher body appreciation scores than girls, in our study, after controlling for the effects of weight status. Nevertheless, as it has been previously hypothesized (Kertechian \& Swami, 2017), these differences might also be conditioned by age and maturational status. In this regard, further research should investigate the role of ageing and maturational development on gender differences in body appreciation, as well as the influence of other unmeasured and potentially confounding factors (e.g. personality traits, Allen \& Walter, 2016).

Although these findings support the use of BAS-2 to measure body appreciation in Brazilian adolescents, two limitations should be highlighted. On the one hand, a convenience sample of adolescents from three Brazilian cities were recruited, thus it is not possible to claim that these results can be generalized to the entire Brazilian adolescent population. On the other hand, we employed a cross-sectional design that prevent from suggesting a causal direction between body appreciation and criterion variables. Further prospective studies are needed to shed light on the relationship between body appreciation-dissatisfaction and different indicators of wellbeing/ill-being.

Despite these limitations, this study contributes to the growing amount of literature on body appreciation providing evidence that supports the one-dimensional structure and reliability of BAS-2, as well as its convergent and incremental validity across different linguistic, cultural, and age groups. The BAS-2 could be useful both for attaining a deeper insight into positive image research as well as for improving clinical practice in the Brazilian context.

\section{Acknowledgments}

The second author was supported by a grant from the Capes/PDSE/ Processo $\mathrm{n}^{\mathrm{o}}$ $88881.135187 / 2016-01$

\section{References}

Allen, M. S., \& Walter, E. E. (2016). Personality and body image: A systematic review. Body Image, 19, 79-88. http://doi.org/10.1016/j.bodyim.2016.08.012

Alleva, J. M., Martijn, C., Veldhuis, J., \& Tylka, T. L. (2016). A Dutch translation and validation of the Body Appreciation Scale-2: An investigation with female university students in the Netherlands. Body Image, 19, 44-48. http://doi.org/10.1016/j.bodyim.2016.08.008 
Atari, M. (2016). Factor structure and psychometric properties of the Body Appreciation Scale2 in Iran. Body Image, 18, 1-4. http://doi.org/10.1016/j.bodyim.2016.04.006

Avalos, L., Tylka, T. L., \& Wood-Barcalow, N. (2005). The Body Appreciation Scale: Development and psychometric evaluation. Body Image, 2(3), 285-297. http://doi.org/10.1016/j.bodyim.2005.06.002

Brown, T. A. (2015). Confirmatory factor analysis for applied research (2nd ed.). New York, NY: The Guilford Press.

Calmeiro, L., Simões, C., Gaspar de Matos, M., \& Gamito, P. (2012). Factorial validity and group invariance of the Portuguese short version of the Social Physique Anxiety Scale in adolescents. Journal of Child and Adolescent Psychology, 3(2), 199-213.

Cohen, J. (1988). Statistical Power Analysis for the Behavioral Sciences (2nd ed.). Hillsdale, New Jersey: Lawrence Erlbaum.

Conde, W. L., \& Monteiro, C. A. (2006). Body mass index cutoff points for evaluation of nutritional status in Brazilian children and adolescents. Jornal de Pediatria, 82(4), 266272. http://doi.org/10.2223/JPED.1502

Diener, E. D., Emmons, R. A., Larsen, R. J., \& Griffin, S. (1985). The satisfaction with life scale. Journal of Personality Assessment, 49(1), 71-75. http://doi.org/10.1207/s15327752jpa4901_13

Kertechian, S., \& Swami, V. (2017). An examination of the factor structure and sex invariance of a French translation of the Body Appreciation Scale-2 in university students. Body Image, 21, 26-29. http://doi.org/10.1016/j.bodyim.2017.02.005

Li, C.-H. (2015). Confirmatory factor analysis with ordinal data: Comparing robust maximum likelihood and diagonally weighted least squares. Behavior Research Methods, 48, 936949. http://doi.org/10.3758/s13428-015-0619-7

Longo, Y., Coyne, I., \& Joseph, S. (2017). The scales of general well-being (SGWB). Personality and Individual Differences, 109, 148-159. http://doi.org/10.1016/j.paid.2017.01.005

Motl, R. W., \& Conroy, D. E. (2000). Validity and factorial invariance of the Social Physique Anxiety Scale. Medicine and Science in Sports and Exercise, 32(5), 1007-1017. http://doi.org/10.1097/00005768-200005000-00020

Muthén, L. K., \& Muthén, B. O. (1998-2015). Mplus Version 7: User's guide (7th ed.). Los Angeles, CA: Muthén \& Muthén.

Raykov, T. (2004). Behavioral scale reliability and measurement invariance evaluation using latent variable modeling. Behavior Therapy, 35, 299-331. http://doi.org/10.1016/S00057894(04)80041-8

Razmus, M., \& Razmus, W. (2017). Evaluating the psychometric properties of the Polish version of the Body Appreciation Scale-2. Body Image, 23, 45-49. http://doi.org/10.1016/j.bodyim.2017.07.004

Sáenz-Alvarez, P., Sicilia, A., González-Cutre, D., \& Ferriz, R. (2013). Psychometric properties of the Social Physique Anxiety Scale (SPAS-7) in Spanish adolescents. The Spanish Journal of Psychology, 16(E86), 1-9. http://doi.org/10.1017/sjp.2013.86

Swami, V., Alías García, A., \& Barron, D. (2017). Factor structure and psychometric properties of a Spanish translation of the Body Appreciation Scale-2 (BAS-2). Body Image, 22, 13-17. http://doi.org/10.1016/j.bodyim.2017.05.002 
Swami, V., Campana, A. N. N. B., Ferreira, L., Barret, S., Harris, A. S., \& Tavares, M. C. G. C. F. (2011). The Acceptance of Cosmetic Surgery Scale: Initial examination of its factor structure and correlates among Brazilian adults. Body Image, 8(2), 179-185. http://doi.org/10.1016/j.bodyim.2011.01.001

Swami, V., Ng, S. K., \& Barron, D. (2016). Translation and psychometric evaluation of a Standard Chinese version of the Body Appreciation Scale-2. Body Image, 18, 23-26. http://doi.org/10.1016/j.bodyim.2016.04.005

Swami, V., \& NG, S.-K. (2015). Factor structure and psychometric properties of the Body Appreciation Scale-2 in university students in Hong Kong. Body Image, 15, 68-71. http://doi.org/10.1016/j.bodyim.2016.04.006

Swami, V., Tudorel, O., Goian, C., Barron, D., \& Vintila, M. (2017). Factor structure and psychometric properties of a Romanian translation of the Body Appreciation Scale-2. Body Image, 23, 61-68. http://doi.org/10.1016/j.bodyim.2017.08.001

Tylka, T. L., \& Wood-Barcalow, N. L. (2015a). The Body Appreciation Scale-2: Item refinement and psychometric evaluation. Body Image, 12(1), 53-67. http://doi.org/10.1016/j.bodyim.2014.09.006

Tylka, T. L., \& Wood-Barcalow, N. L. (2015b). What is and what is not positive body image? Conceptual foundations and construct definition. Body Image, 14, 118-129. http://doi.org/10.1016/j.bodyim.2015.04.001

Voelker, D. K., Reel, J. J., \& Greenleaf, C. (2015). Weight status and body image perceptions in adolescents: current perspectives. Adolescent Health, Medicine and Therapeutics, 6, 149-158. http://doi.org/10.2147/AHMT.S68344

Webb, J. B., Wood-Barcalow, N. L., \& Tylka, T. L. (2015). Assessing positive body image: Contemporary approaches and future directions. Body Image, 14, 130-145. http://doi.org/10.1016/j.bodyim.2015.03.010

West, S. G., Taylor, A. B., \& Wu, W. (2012). Model fit and model selection in structural equation modeling. In R. H. Hoyle (Ed.), Handbook of Structural Equation Modeling (pp. 209-231). New York, NY: Guilford.

Zanon, C., Bardagi, M. P., Layous, K., \& Hutz, C. S. (2014). Validation of the Satisfaction with Life Scale to Brazilians: Evidences of measurement noninvariance across Brazil and US. Social Indicators Research, 119(1), 443-453. http://doi.org/10.1007/s11205013-0478-5 